\title{
Current Management of Tics and Tourette Syndrome: Behavioral, Pharmacologic, and Surgical Treatments
}

\author{
Andrew Billnitzer ${ }^{1} \cdot$ Joseph Jankovic ${ }^{1}$ \\ Published online: 27 August 2020 \\ (C) The American Society for Experimental NeuroTherapeutics, Inc. 2020
}

\begin{abstract}
Tourette syndrome is a heterogeneous neurobehavioral disorder manifested by childhood-onset motor and phonic tics, often accompanied by a variety of behavioral comorbidities, including attention deficit and obsessive compulsive disorder. Treatment must be tailored to the needs and goals of the individual patients and their families. All patients should receive education on the condition and, if possible, engage behavioral therapy targeted towards tics and/or comorbidities. Pharmacological therapies, such as alpha agonists, topiramate, and vesicular monoamine transport type 2 inhibitors, are generally used as first-line therapies in patients with troublesome tics that are not controlled by behavioral therapy or when the latter is not available or accessible. Botulinum toxin injections can be used in patients with bothersome focal tics. Second-line therapy includes antipsychotics, such as fluphenazine, aripiprazole, risperidone, and ziprasidone. These medications are generally efficacious but carry the risk of metabolic syndrome, tardive dyskinesia, and other side effects. Much more research is needed before novel therapies such as cannabis-derived products or transcranial magnetic stimulation can be recommended. There is promise in ongoing clinical trials with D1 receptor antagonist ecopipam and other experimental therapeutics. Patients with tics that are refractory to conventional treatments may be candidates for deep brain stimulation, but further studies are needed to determine the optimal target selection.
\end{abstract}

Key Words Tourette syndrome (TS) · Tics · Deep brain stimulation (DBS) $\cdot$ Vesicular monoamine transport inhibitor (VMAT2) · Comprehensive behavioral therapy in tics (CBIT)

\section{Introduction}

Tourette syndrome (TS) is a neurodevelopmental disorder defined by the Diagnostic and Statistical Manual of Mental Disorders (DSM-5) by the presence of both motor and phonic tics prior to the age of 18 and persisting for a period of greater than 12 months without a secondary cause [1]. It is more common in males compared to females $(3: 1)$, with a reported prevalence ranging between 0.3 and $1 \%$ [2]. TS is often accompanied by a variety of behavioral comorbidities such as obsessive compulsive disorder (OCD) or attention deficit hyperactivity disorder (ADHD). The tics and behavioral

Joseph Jankovic

josephj@bcm.edu; https://www.jankovic.org

1 Parkinson's Disease Center and Movement Disorders Clinic, Department of Neurology, Baylor College of Medicine, 7200 Cambridge, Suite 9A, Houston, TX 77030-4202, USA comorbidities can lead to marked impairment in family and social interactions and school and job performance, and often seriously impact patients' quality of life. Treatment strategies must be individualized and tailored to the patient's specific needs, and should be accompanied by education to improve understanding of TS and the patient's specific goals and expectations (Fig. 1) [3].

\section{Nonpharmacological Treatments}

\section{Patient Education and Counseling}

All newly diagnosed patients and their families should first be educated about TS and provided with reliable informational resources (e.g., the Tourette Association of America; https:// tourette.org/) to facilitate better understanding of the condition. Topics to be discussed should include the neurological (brain) rather than the psychological origin of 
Fig. 1 Suggested treatment algorithm for the management of tics associated with Tourette syndrome

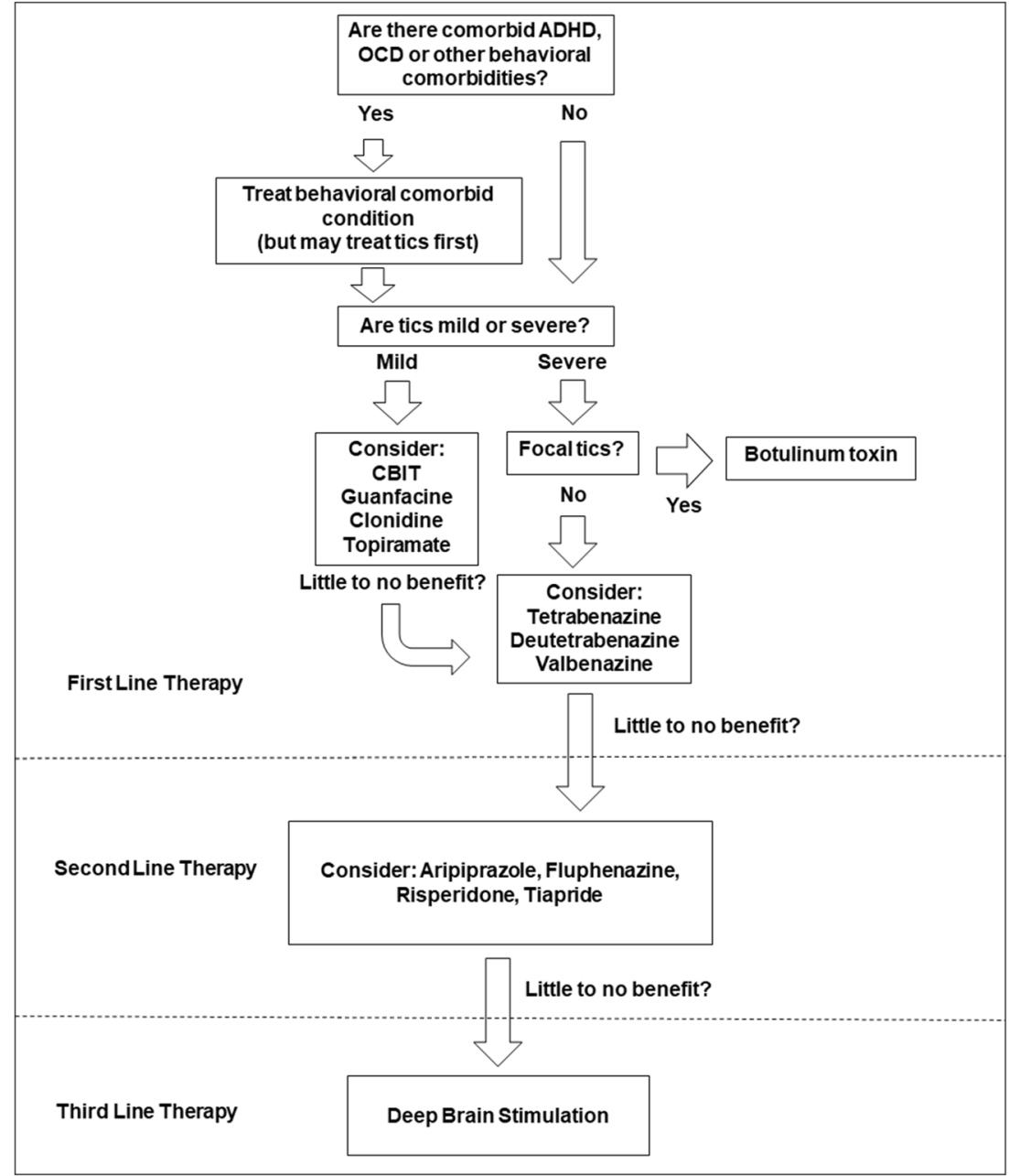

tics, the waxing and waning of the nature of symptoms, the natural history of progression, the potential for remission after age 18 , and the various behavioral, medical, and surgical therapeutic options. The natural history of TS is quite variable, but generally, tic severity tends to peak just before puberty (i.e., age 10-12 years) and decline after adolescence. As such, watchful observation or behavioral therapy can be considered as acceptable alternatives to medications, particularly in early and mild cases [4].

Because therapy must be individualized, discussion should focus on the specific symptoms that are most troublesome to the particular patient. Although tics are often the presenting feature of TS, it is important to recognize and highlight the broad spectrum of motor and phonic tics from simple to complex, and the broad variety of comorbidities. For example, some complex motor tics may be accompanied by selfinjurious behaviors, noted in at least a third of all patients with TS, particularly in the setting of underlying OCD [5].

Furthermore, complex phonic and motor tics may be characterized by inappropriate or obscene utterances (coprolalia) or gestures (copropraxia). Although coprophenomenon is relatively uncommon, occurring in less than $20 \%$ of all patients with TS, this feature of TS could potentially have serious impact on social interactions, work performance, and academic activities. Encouraging patients and families to discuss potential behavioral and educational interventions with teachers and school administrators can be beneficial [6]. Accommodations afforded by section 504 of the U.S. Rehabilitation Act of 1973 should help students achieve their full academic potential. These include, but are not limited to, preferential seating; extended time on tests and assignments; reduced homework or classwork; verbal, visual, or technology aids; modified textbooks or audio-video materials; behavior management support; adjusted class schedules or grading; verbal testing; and pre-approved nurse's office visits.

Educational materials for students, parents, and teachers, such as those provided by the Tourette Association of America, should be made available from onset as they can lead to more positive impacts and attitudes among patients, peers, and teachers regarding TS [4]. A meta-analysis of 22 studies that evaluated the impact of providing educational information and programs on TS and ADHD to patients, peers, and educators found that providing educational materials can improve knowledge and attitudes towards TS in both adults and children [7]. 


\section{Comprehensive Behavioral Intervention for Tics}

Comprehensive behavioral intervention for tics (CBIT) is a program consisting of habit reversal training, relaxation training, and functional interventions designed to address situations which may worsen tics. It involves training patients to perform a competing behavior to avoid a tic whenever they feel a premonitory sensation [8]. The premonitory urge, a sensory phenomenon experienced by most TS patients just prior to execution of motor and phonic tics, has recently been linked to the dysfunction of the insula, particularly the anterior-dorsal region [9]. Sensory aspects of movement disorders, such as the premonitory sensory phenomenon in TS, have been increasingly recognized over the past few years [10].

CBIT has received a "high confidence" recommendation in clinical practice guidelines issued by the American Academy of Neurology (AAN) (Table 1) [4]. One trial recruited 126 children (ages 9-17) to participate in either CBIT or supportive counseling in 8 sessions over 10 weeks [11]. Compared to supportive counseling, the CBIT group showed significant improvement in tic scores with reduction of 4.1 points, $95 \%$ confidence interval (CI) 2.0, 6.2, as rated by the Yale Global Tic Severity Scale Total Tic Score (YGTSS-TTS) (range 050). Comparable improvement was seen in a trial involving an older population [12]. In this study, 122 patients, ages 16 to 69 , were randomized to 8 sessions of CBIT or 8 sessions of supportive treatment over 6 weeks. CBIT was associated with a greater decrease in the YGTSS-TTS (from $24 \pm 6.47$ to 17.8 \pm 7.32 ) compared with controls (from $21.8 \pm 6.95$ to $19.3 \pm$ 7.40 ) with $38 \%$ of patients in the treatment group reporting much improvement in their symptoms compared to $6.4 \%$ in the control group. In both studies, the benefits of CBIT were sustained at 6 months. A meta-analysis of CBIT involving 8 randomized controlled trials involving 438 patients found that the treatment effect for CBIT (standardized mean difference $(\mathrm{SMD})=0.67 ; 95 \%$ CI $0.22,1.12)$ was comparable to the treatment effect seen in randomized controlled trials of antipsychotic drugs for the treatment of tics [13]. A larger effect size was seen with older participants, in participants who had more therapeutic contact, and in participants who did not have comorbid ADHD.

Due to the nature of the therapy, potential barriers to CBIT include a lack of trained professionals, poor or no insurance coverage, and time and compliance demands on family and patients to adhere to the therapy. Other factors that may influence response to therapy include patients' age and selfmotivation $[3,8]$. Because the effect size for CBIT treatment is similar to that of most medications, it is recommended as first-line therapy to those patients who have access to this form of therapy, which unfortunately is a minority of those who would potentially benefit $[3,4,8]$. There is an ongoing clinical trial entitled "Internet-based CBIT for Children With Chronic Tics" (Clinical Trials ID NCT04087616) directed at evaluating the efficacy of CBIT when delivered via the internet in efforts to expand access [14].

\section{Pharmacological Treatments for Tics}

In cases in which CBIT is not feasible or not readily accessible, or of limited benefit, or the patient is unable to cooperate

Table 1 Currently available treatments in Tourette syndrome

\begin{tabular}{|c|c|c|c|}
\hline Treatment & $\begin{array}{l}\text { AAN } \\
\text { recommendation } \\
\text { (level of } \\
\text { evidence) [4] }\end{array}$ & Potential side effects & Special considerations \\
\hline CBIT & $\mathrm{B}$ & None & Dependent on patient motivation \\
\hline Alpha agonist & $\mathrm{B}$ & Sedation, bradycardia & $\begin{array}{l}\text { May be more effective with comorbid ADHD, requires } \\
\text { tapering to avoid rebound hypertension }\end{array}$ \\
\hline Topiramate & B & $\begin{array}{l}\text { Cognitive language problems, somnolence, weight } \\
\text { loss, nephrolithiasis }\end{array}$ & - \\
\hline Antipsychotics & $\mathrm{C}$ & $\begin{array}{l}\text { Weight gain, extrapyramidal side effects, tardive } \\
\text { dyskinesia, QTC prolongation }\end{array}$ & $\begin{array}{l}\text { Requires cardiac monitoring, requires tapering to avoid } \\
\text { withdrawal dyskinesia, tardive syndrome }\end{array}$ \\
\hline $\begin{array}{l}\text { VMAT2 } \\
\text { inhibitors }\end{array}$ & - & Drowsiness, depression, parkinsonism & $\begin{array}{l}\text { Often costly and not covered by insurance, do not carry a } \\
\text { risk of tardive dyskinesia }\end{array}$ \\
\hline BoNT & $\mathrm{C}$ & $\begin{array}{l}\text { Temporary weakness, hypophonia at the site of } \\
\text { injection }\end{array}$ & Useful for bothersome focal tics or phonic tics \\
\hline $\begin{array}{l}\text { Cannabis-based } \\
\text { medications }\end{array}$ & $\mathrm{C}$ & $\begin{array}{l}\text { Dizziness, dry mouth, fatigue, impaired driving } \\
\text { ability }\end{array}$ & $\begin{array}{l}\text { Not recommended for children. Adult use only and where } \\
\text { legislation allows }\end{array}$ \\
\hline DBS & $\mathrm{B}$ & $\begin{array}{l}\text { Hardware infection/removal, worsening of } \\
\text { psychiatric conditions }\end{array}$ & $\begin{array}{l}\text { For refractory cases, all patients should be screened by a } \\
\text { multidisciplinary board before implantation }\end{array}$ \\
\hline
\end{tabular}

$\mathrm{CBIT}=$ comprehensive behavioral intervention in tics; VMAT2 = vesicular monamine transporter 2; BoNT = botulinum neurotoxin; DBS = deep brain stimulation 
Table 2 Experimental therapeutics in Tourette syndrome

\begin{tabular}{|c|c|c|c|c|c|c|c|}
\hline Class & Intervention & Trial ID & Trail design & Phase & $\begin{array}{l}\text { Age group } \\
\text { (years) }\end{array}$ & $\begin{array}{l}\text { Treatment } \\
\text { period }\end{array}$ & Primary outcome \\
\hline $\begin{array}{l}\text { 2nd-generation } \\
\text { antipsychotic }\end{array}$ & Aripiprazole & NCT03661983 & $\begin{array}{l}\text { Randomized placebo } \\
\text { controlled }\end{array}$ & $3 b / 4$ & $6-17$ & 12 weeks & YGTSS-TTS \\
\hline Anti-serotonergic & Ondansetron & NCT03239210 & $\begin{array}{l}\text { Randomized placebo } \\
\text { controlled }\end{array}$ & 4 & $18-60$ & 4 weeks & $\begin{array}{l}\text { Sensory phenomena } \\
\text { severity scale }\end{array}$ \\
\hline $\begin{array}{l}\text { D1 receptor } \\
\text { antagonist }\end{array}$ & Ecopipam & NCT04007991 & $\begin{array}{l}\text { Randomized placebo } \\
\text { controlled }\end{array}$ & $2 b$ & $6-17$ & 12 weeks & YGTSS-TTS \\
\hline $\begin{array}{l}\text { D1 receptor } \\
\text { antagonist }\end{array}$ & Ecopipam & NCT04114539 & Open label extension & $2 b$ & $6-18$ & 12 months & Incidence of $\mathrm{AE}$ \\
\hline Cannabinoid & THC, CBD & NCT03247244 & $\begin{array}{l}\text { Placebo-controlled } \\
\text { crossover study }\end{array}$ & 2 & $18-65$ & - & $\begin{array}{l}\text { Modified rush } \\
\text { Video-based } \\
\text { Tic rating Scale }\end{array}$ \\
\hline Cannabinoid & Nabiximols & NCT03087201 & $\begin{array}{l}\text { Randomized placebo } \\
\text { controlled }\end{array}$ & 3 & $>18$ & 13 weeks & YGTSS-TTS \\
\hline DBS & Thalamic stimulation & NCT01817517 & Open label & N/A & $>15$ & 1 year & YGTSS \\
\hline DBS & CMT stimulation & NCT02056873 & Open label & N/A & $>21$ & 24 months & YGTSS-TTS \\
\hline $\mathrm{tDCS}$ & $\begin{array}{l}\text { Direct-current } \\
\text { stimulation of SMA }\end{array}$ & NCT03401996 & $\begin{array}{l}\text { Randomized placebo } \\
\text { controlled }\end{array}$ & $\mathrm{N} / \mathrm{A}$ & $>16$ & 1 week & YGTSS-TTS \\
\hline rTMS & rTMS of the SMA & NCT04128397 & Open label & N/A & $6-65$ & 5 days & YGTSS \\
\hline rTMS & rTMS of the SMA & NCT03844919 & $\begin{array}{l}\text { Randomized placebo } \\
\text { controlled }\end{array}$ & $\mathrm{N} / \mathrm{A}$ & $6-18$ & 7 weeks & YGTSS \\
\hline rTMS & rTMS of the SMA & NCT03642951 & $\begin{array}{l}\text { Randomized placebo } \\
\text { controlled }\end{array}$ & $\mathrm{N} / \mathrm{A}$ & $8-20$ & 2 months & YGTSS \\
\hline
\end{tabular}

$\mathrm{THC}=$ tetrahydrocannabinol $\mathrm{CBD}=$ cannabidiol YGTSS $=$ Yale Global Tic Severity Scale DBS = deep brain stimulation; CMT = centromedial thal amus; tDCS = transcranial direct current stimulation; rTMS = repetitive transcranial magnetic stimulation; SMA = supplemental motor area

with therapy (i.e., too young), pharmacological therapy is the next option. There is a remarkable paucity of well-designed, controlled, clinical trials that provide evidence supporting pharmacological treatment for tics. Indeed, there are only three Cochrane reviews of trials assessing three separate pharmacotherapies, pimozide, cannabis, and onabotulinum toxin, for which no firm conclusions could be drawn regarding treatment recommendations [15-17]. As such, guidelines for the pharmacological treatment of tics, such as those recently provided by the AAN, are based on expert consensus about initiation of pharmacological therapy [4]. Starting pharmacological treatments should include discussion of potential risks and benefits with the patients and their family and should align with their collective goals.

\section{Alpha-2 Agonists}

Multiple studies have shown that alpha-2 agonists, clonidine and guanfacine, have been effective in the treatment of TS, primarily in children [18-23]. Because of their relatively good safety profile, these drugs, usually prescribed by pediatricians or child psychiatrists, are often used as first-line therapy in patients with relatively mild tics. We also use them in patients with mild ADHD or impulse control disorder.

Clonidine has shown effectiveness in several randomized placebo control trials. In a multicenter 16-week, randomized, double-blind, placebo-controlled trial (RDBPCT) of 136 children with ADHD and chronic tic disorder, patients were randomized to receive clonidine alone, methylphenidate alone, clonidine plus methylphenidate, or placebo [21]. Change in the YGTSS (range $0-100$ ) was the primary outcome measure for tics. All treatment groups were superior when compared to placebo in reducing tic severity with the clonidine plus methylphenidate treatment group (reduction of $11.2 ; 98.3 \% \mathrm{CI}-$ $0.1,22.5$ ) and the clonidine-alone treatment group (reduction of $10.9 ; 98.3 \%$ CI $2.1,19.7)$ showing the greatest improvement. Furthermore, the study provided no evidence that methylphenidate worsened tics despite the common observation that central nervous system (CNS) stimulants trigger or exacerbate tics. The efficacy of clonidine in reducing tics was further supported by another RDBPCT involving 437 patients with tics or TS [23]. Patients who were randomized to receive a clonidine transdermal patch showed a significant reduction in tics as measured by the YGTSS when compared to placebo (reduction of $11.53 \pm 8.22$ vs $10.72 \pm 7.50$ ).

Guanfacine was found to be effective in reducing tics in a small open-label trial of 10 TS patients with ADHD. Duration of follow-up ranged from 4 to 20 weeks. At the end of the study, there was a $37.6 \%$ decrease in the mean YGTSS phonic tic score (range 0-25) (mean reduction $7.8 \pm 4.6$ ) [19]. In a RDBPCT, 34 patients (mean age 10.4 years) with tics and comorbid ADHD were assigned to receive guanfacine or 
placebo for 8 weeks [18]. At the end of the trial, tic severity, measured by the YGTSS-TTS, was decreased by $31 \%$ in the treatment group compared to the placebo group, which showed no improvement. Another RDBPCT, however, failed to show similar efficacy [22]. In this trial, 34 patients with chronic tic disorder (age 6-17 years) were assigned to receive guanfacine extended release or placebo for 8 weeks. No significant difference was seen in the YGTSS between groups at the end of the study.

Based on existing published data, it appears that alpha agonists are more efficacious in TS patients with comorbid ADHD which may explain the results of the above negative trial. In a meta-analysis of 4 trials of clonidine and 2 trials of guanfacine, a significant benefit in reduction of tics was noted $(\mathrm{SMD}=0.31 ; 95 \%$ CI $0.15,0.48 ; p<0.001$ when alpha-2 agonist was compared to placebo) [24]. A greater effect was seen in trials that enrolled subjects with tics and ADHD $(\mathrm{SMD}=0.68 ; 95 \% \mathrm{CI} 0.36,1.01)$ than in trials that excluded subjects with ADHD (SMD $=0.15 ; 95 \% \mathrm{CI}-0.06,0.36$ ). When this data was later stratified in subgroup analysis, the presence of comorbid ADHD led to a greater effect of alpha-2 agonist in reducing tics $(\alpha=0.0053 ; 95 \%$ CI $0.0015,0.0091)$. Neither clonidine nor guanfacine has been found to be superior to the other in the reduction of tics; however, guanfacine appears to be better tolerated and cause less sedation than clonidine [25].

The most common side effects of alpha-2 agonists include sedation and drowsiness [3]. Other potential side effects include headache, dry mouth, irritability, bradycardia, and hypotension as well as prolonged QTC, particularly with the use of guanfacine XR [3, 4].

\section{Topiramate}

There have been several studies that have found topiramate to be a viable treatment option for tics in TS [26, 27]. In a pilot RDBPCT, 29 patients with TS, age 7 to 65 years, were randomized to receive either topiramate or placebo for 10 weeks [27]. Compared to the placebo group, there was a significant reduction of the YGTSS-TTS by $14.29 \pm 10.47$ points from baseline compared to only a $5.0 \pm 9.88$ point improvement in the placebo group. Additionally, patients in the topiramate group showed improvement in premonitory urge, but this effect was not quantified.

A meta-analysis evaluating 14 trials involving 1003 patients, age 7 to 17 years, evaluated the use of topiramate for treatment of tics compared to conventional treatment [28]. All trials included a drug comparator; 12 used haloperidol and 2 used tiapride as comparators. In 3 trials that used the YGTSS as an outcome measure, there was a significant improvement of tics (reduction of mean 7.74 points in the total YGTSS score; $95 \%$ CI 10.49, 4.99) favoring topiramate compared to a control group. In the remainder of the studies, no superiority was seen when comparing topiramate to either haloperidol or tiapride [28].

Topiramate is currently recommended for use in relatively mild cases of TS or when other therapy cannot be tolerated. The typical dose is 25 to $150 \mathrm{mg}$ daily. Side effects include cognitive and language problems, weight loss, renal stones, and somnolence [4].

\section{Antipsychotics}

The use of antipsychotic medications, which act primarily by blocking dopamine receptors, for treatment of tics dates back to the late 1960s when haloperidol was first approved by the US Food and Drug Administration (FDA) for treatment of TS [8]. After haloperidol, pimozide was the second antipsychotic approved by the FDA for the treatment of TS, and in 2014, the FDA approved aripiprazole as the third drug for TS. Several studies have evaluated second- and third-generation antipsychotics such as ziprasidone, risperidone, and aripiprazole and found them to be effective in reducing the frequency and intensity of tics when compared to placebo [29-33].

Aripiprazole was FDA approved for the treatment of TS following a 2013 RDBPCT involving 61 subjects (ages 6-18) [30]. Patients in the treatment group had a reduction in the YGTSS-TTS of $15.0 \pm 8.4$ compared to a $9.6 \pm 8.8$ reduction in the placebo group. In 2017, Sallee et al. reported the results of phase 3 RDBPCT of aripiprazole involving 133 patients with TS [31]. At week 8 of the trial, the treatment difference in YGTSS-TTS $v$ s placebo was $-6.3(95 \%$ CI 10.2,-2.3) in the low-dose group (5-10 mg/day) and -9.9 (95\% CI 13.8, - 5.9) in the high-dose group (10-20 mg/day). The most common adverse events were sedation and fatigue. Although no tardive dyskinesia was reported in these trials, it is now well recognized that patients treated with aripiprazole and other antipsychotics, with possible exception of clozapine, may develop tardive dyskinesia as a result of their dopamine receptor blocking action [34].

Risperidone, although not FDA approved, has also been shown to be efficacious in the treatment of tics. In one RDBPCT, 48 adolescent and adult TS patients were randomized to risperidone or placebo for 8 weeks [32]. At the end of the study, $60.8 \%$ of patients in the treatment group showed at least one point improvement in the Global Severity Rating of the Tourette Syndrome Severity Scale, compared to $26.1 \%$ in the placebo group, significantly favoring risperidone. In another RDBPCT, 34 patients with TS (age 6-62 years) were randomized to risperidone or placebo for 8 weeks [33]. At the end of this study, there was a $36 \%$ mean reduction in the YGTSS-TTS in the treatment group (mean change from $26.0 \pm 5.06$ to $17.6 \pm 4.75$ ) compared to a $7 \%$ reduction in the placebo group (mean change from $27.4 \pm 8.51$ to $25.4 \pm$ 8.75). Notably, a mean increase in body weight of $2.8 \mathrm{~kg}$ was noted in the risperidone group. In a 6-week open label trial, 14 
TS patients (age 7-14 years) were administered ziprasidone with a 30\% reduction in YGTSS-TTS by the end of the study (mean change from $31.92 \pm 7.32$ to $22.50 \pm 9.37$ ) [35]. Side effects included drowsiness, sedation, and a mean weight gain of $4.1 \mathrm{~kg}$.

A meta-analysis of 10 studies evaluated the use of antipsychotic medications for the treatment of tics in TS [24]. Trials compared haloperidol, pimozide, risperidone, and ziprasidone to placebo. The meta-analysis demonstrated that there was a medium to large treatment effect of the antipsychotic agent improving tic symptoms when compared to placebo $(\mathrm{SMD}=0.58 ; 95 \%$ CI $0.36,0.80)$. A stratification analysis comparing efficacy in between antipsychotic agents did not find significant differences between the various antipsychotics.

Before the advent of the class of drugs that act as dopamine depleters by inhibiting presynaptic vesicular membrane transport type 2 (VMAT2) (discussed below), we have used fluphenazine as the main dopamine receptor blocking drug in the treatment of TS [36]. In a retrospective chart review, $268 \mathrm{TS}$ patients (age 4-70) were initiated on fluphenazine for management of their tics; 211 (80.5\%) reported moderate to marked improvement in their symptoms based on a 5-point rating scale comparing reduction in tics to the baseline visit $(1=$ marked reduction, $5=$ worsening of tics). The most common side effects were drowsiness or fatigue. Although no cases of tardive dyskinesia were noted in this study (average duration of treatment of $2.6 \pm 3.2$ years), fluphenazine, like other antipsychotics, can cause this iatrogenic complication.

Besides tardive dyskinesia, there are many other risks associated with prescribing antipsychotic medications, including weight gain and metabolic syndrome, prolactin increase, and QTC prolongation [4]. In one retrospective study that evaluated siblings with discordant TS or chronic tic disorder, 7804 patients were found to have a higher risk of metabolic or cardiovascular disorders compared to sibling controls (hazard ratio $1.37 ; 95 \% \mathrm{CI} 1.24,1.51)$ and the general population (HR $1.99 ; 95 \%$ CI 1.90, 2.09) [37]. Although this was apparently not related to long-term ( $>1$ year) use of antipsychotics, it is important to keep in mind that these drugs can cause weight gain and metabolic syndrome.

If antipsychotics are ineffective or associated with adverse effects, they should be gradually discontinued to avoid withdrawal and tardive dyskinesia $[4,38,39]$. Given the associated risk of metabolic syndrome and tardive dyskinesia, and the need for periodic cardiac monitoring, antipsychotic agents should be considered second-line therapy after first-line agents have failed (Fig. 1).

\section{VMAT2 Inhibitors}

VMAT2 inhibitors block the vesicular monoamine transporter type 2 which is normally necessary for packing monoamines, such as dopamine, into presynaptic vesicles for release into the synaptic cleft [40]. The result of VMAT2 inhibitors is presynaptic striatal dopamine depletion and a reduction of dopamine release. Medications in this class include tetrabenazine, deutetrabenazine, and valbenazine. Deutetrabenazine has been approved by the FDA to treat Huntington's chorea and tardive dyskinesia, and valbenazine has been approved to treat tardive dyskinesia. However, VMAT2 inhibitors have been also used successfully off label for treatment of a broad variety of hyperkinetic movement disorders, including tics [40, 41].

In an open-label, pilot, study of 23 patients (age 12-18 years) with TS, up to $36 \mathrm{mg}$ daily of deutetrabenazine (mean daily dose $32.1 \mathrm{mg}$ ) was administered over an 8-week period [42]. Following treatment, patients had a $37 \%$ reduction in tic severity measured by the YGTSS-TTS (reduction of $11.6 \pm 8.2$ ). In one retrospective chart review, 77 TS patients (mean age 77) were prescribed tetrabenazine off label for treatment [43]. Among those prescribed the medication, $80 \%$ reported improvement in their symptoms as measured by a 5-point rating scale ( $1=$ marked reduction, $5=$ worsening of tics). In another retrospective chart review of 135 patients, 67 of whom had TS, treated with tetrabenazine, deutetrabenazine, or valbenazine for tics, when surveyed about severity of symptoms before and after treatment, the majority of respondents reported improvement as measured by a 4 -point Likert scale $(1=$ normal or mildly ill, $4=$ severely ill) [41].

Despite the improvement observed in open-label studies and "real-world" experience, 2 recent RDBPCTs, 30,046 ARTISTS 1 (flexible-dose titration), and 30,060 ARTISTS 2 (fixed dose) were negative [44]. In the ARTIST 1 trial, 119 patients were enrolled and, after initial dose titration, were followed for a total of 12 weeks, whereas in the ARTIST 2 trial, 158 patients were enrolled in a fixed-dose design and followed for 8 weeks. Although reduction in the YGTSSTTS and responder analyses favored deutetratrabenazine over placebo, the primary endpoint was not met in either study. Although the full reports have not yet been published, this unfortunately parallels the findings from similar, yet unpublished, studies with valbenazine in pediatric and adult TS populations. There are many possible explanations for the unexpected results, including difficulties in assessing a highly variable disorder and subtherapeutic dosing. The latter explanation is supported by the observation of a very low frequency of adverse effects, specifically no evidence of depression or suicidal ideation.

Side effects of VMAT2 inhibitors, noted in long-term observational studies and real-world experience, include depressive symptoms, akathisia, weight gain, insomnia, and parkinsonism [41]. However, unlike D2 receptor antagonists, VMAT2 inhibitors do not carry a risk of developing tardive dyskinesia [40]. There is also supportive evidence that they cause less weight gain, especially in the pediatric population, than antipsychotic therapy [45]. 
The off-label use of VMAT2 inhibitors in TS and other hyperkinetic movement disorders is associated with many hurdles to prescribers and patients that limit potential widespread utilization of the drugs. Such barriers include high out-of-pocket cost, insurance denials, lengthy appeals, and requiring trials of older medications that may be less efficacious or carry more side effects before the VMAT2 inhibitor is approved [41]. Given the efficacy observed by many clinicians around the world in a large number of TS patients, good tolerability, minimal side effect profile, and low or no risk of tardive dyskinesia, VMAT2 inhibitors should be considered viable alternative therapy to antipsychotic medications as first-line therapy in patients with troublesome tics, although, given the recent negative trials, FDA approval in the near future is unlikely.

\section{New and Emerging Therapies}

\section{D1 Receptor Antagonist}

Although all available dopamine receptor blocking drugs act primarily by antagonizing D2 receptors, there is a possibility that inhibition of D1 receptors may also have beneficial effects. The D1 receptor antagonist ecopipam was initially developed in the 1980 s as a potential antipsychotic therapy, but it failed in trials for schizophrenia [46, 47]. It has, however, shown promise in treatment of tics. In one open-label trial, 18 adults (mean age 36.2 years) were administered $100 \mathrm{mg}$ ecopipam for 8 weeks [48]. At the end of the study, there was a significant reduction in YGTSS-TTS when compared to baseline (from $30.6 \pm 8.8$ to $25.3 \pm 9.2 ; p=0.0004$ ). There was also an improvement of the YGTSS impairment score (from $29.7 \pm 10.9$ to $22.8 \pm 13.7 ; p=0.04$ ). Most common adverse events were sedation and fatigue, insomnia, anxiety, headache, and muscle twitching.

In a phase $2 \mathrm{~b}$ RDBPCT, 40 adolescents (aged 7-17) were administered ecopipam for 30 days [49]. When compared to placebo, ecopipam was associated with a reduction in YGTSS-TTS of 3.2 points (95\% CI 6.1 to 0.3 ) which was considered clinically meaningful. No weight gain or drug-induced movement disorders were seen, and the medication was otherwise well tolerated. In the current, larger, phase $2 \mathrm{~b}$, multicenter RDBPCT (D1AMOND), ecopipam is being evaluated for the efficacy and safety in children and adolescents with TS (Clinical Trials ID NCT04007991) (Table 2) [50]. If ecopipam is found to carry low risk of weight gain or metabolic syndrome and is otherwise well tolerated, it may be considered in the future as an early line therapy in TS.

\section{Cannabis-Based Medications}

Cannabis-based therapy has been explored in the past as a potential treatment option for TS. In a RDBPCT of 12 adult patients with TS, patients given delta 9-tetrahydrocannabinol reported significant improvement in their tics and obsessive compulsive behavior 3 to $4 \mathrm{~h}$ after treatment when compared to placebo based in the Tourette syndrome symptom list $(-14$ \pm 10.97 change from baseline in the treatment group $v s-4.69$ \pm 6.69 in the placebo group) [51]. There was also a nonsignificant trend towards improvement in tics in the treatment group seen on the Shapiro Tourette syndrome severity scale, the Tourette syndrome global scale, and the YGTSS. Serum tetrahydrocannabinol (THC) concentrations were also measured during the study and correlated with improvement in tics as measured by the examiner [51]. In a follow up RDBPCT over 6 weeks, involving an additional 24 patients, there was again a trend towards improvement in the THC treatment group compared to the placebo group at the end of the study, though this was not found to be statistically significant [52].

As the legislative landscape has changed, there has been more interest in exploring cannabis-based medications as a potential therapy; however, there is a paucity of welldesigned and well-conducted studies. In one cross-sectional survey of 42 patients with TS who were already undergoing treatment with medical cannabis, all patients interviewed reported some improvement with tics while taking medical cannabis when asked about the efficacy of medical cannabis in treating their symptoms (mean response $=3.85 \pm 1.41$ out of a 5 -point Likert scale, $1=$ worsening symptoms, $5=$ favorable response) [53]. Adverse effects led to discontinuation of treatment in 10 patients, including one patient because of an episode of psychosis. Other patients who discontinued treatment had side effects that included hallucinations (4 patients), irritability and confusion (6 patients), and subjective cognitive decline (7 patients).

A recent 12-week RDBPCT evaluating the use of THX-10 (dronabinol, tetrahydrocannabinol, palmitoylethanolamide) in adult TS patients has apparently met its primary endpoint and led to significant improvement in symptoms, but further information is needed [54].

In the setting of renewed interests, there are several ongoing RDBPCTs evaluating cannabis and its derivative products. The CANNAbinoids in the Treatment of TICS (CANNA-TICS) study is evaluating the use of nabiximols to treat chronic tic disorders (Clinical Trials ID NCT03087201) [55]. The Safety and Efficacy of Cannabis in Tourette Syndrome trial is evaluating medical cannabis in adults with TS (Clinical Trials ID NCT03247244) (Table 2) [56].

ABX-1431 is a monoacylglycerol lipase inhibitor that regulates endocannabinoid and eicosanoid signaling pathways. It has recently been shown to be well tolerated in phase 1 clinical studies, and data from an exploratory phase $1 \mathrm{~b}$ study suggest 
that it has potential for treatment of symptoms of TS in adult patients [57]. It is currently undergoing phase 2 trials in TS (clinical trial ID NCT03625453) (Table 2) [58].

As of now, there is limited evidence that dronabinol reduces tic severity when compared to placebo. There is insufficient evidence on the use of cannabis-based compounds nabiximol, nabilone, and cannabidiol for treatment of tics. The most common side effects seen with these medications include dry mouth, dizziness, and fatigue. For patients who are interested, physicians should direct them to appropriate medical and legal information [4]. Much more evidence is needed before cannabis-based medications can be safely recommended to patients for management of TS.

\section{Alternative Medications}

Given concerns over treatment side effects, more patients and their families have pursued complementary and alternative medicine (CAM) with the perception that such practices are "natural" and therefore safe [59]. In a survey of 110 TS patients ( $<18$ years old) and caregivers, 69.1\% reported using CAM therapy [59]. The most commonly reported CAM therapies were stress management $(44.6 \%)$, herbal medicine (18.2\%), homeopathy (18.2\%), and meditation (9.1\%). Of those patients participating in CAM therapy, $93 \%$ reported improvement in tics.

Several clinical trials have evaluated the benefit of the herbal medicines Qufeng Zhidong Recipe (QZR) and Ningdong granules. In a meta-analysis of 4 randomized control trials (2 trials involving QZR and 2 involving Ningdong granules), QZR had significant effects across 2 trials in reducing YGTSS-TTS score when compared to a combination of haloperidol and trihexyphenidyl ( $n=142$; weighted mean difference $=-18.34 ; 95 \%$ CI $-23.07,-13.60$ ) [60]. When compared to placebo, Ningdon granules were found to lead to a significant reduction in YGTSS-TTS compared to placebo (6.52; 95\% CI - 9.80, - 3.24); however, no such difference was found when compared to treatment with haloperidol. Notably all 4 studies evaluated in the meta-analysis were noted to be at high risk of bias, with only 1 of the 4 studies being a blinded study.

One multisite RDBPCT evaluated the herbal medicine 5-Ling granule in 608 TS patients (aged 5-18) [61]. Patients were randomized to receive 5-Ling granule, tiapride, or placebo for 8 weeks. At 8 weeks, patients in the 5-Ling granule group showed significant improvement in the YGTSS compared to placebo (effect size $=0.608)$, but no difference was observed when compared to tiapride (effect size $=0.075$ ). Notably, patients in this study that met inclusion criteria needed to have a condition known in traditional Chinese medicine as "excessive subtype disorder," a condition for which there does not exist a western medicine equivalent.
Patients with common TS comorbidities, ADHD and OCD were also excluded.

Due to concerns about the generalizability of the 5-Ling granule study and multiple unknowns regarding the safety of ingredients used in these herbal compounds, the AAN guidelines do not offer formal recommendations on the use of Chinese medicine products [4]. They, however, assigned "moderate confidence" to 5-Ling granule and Ningdong granule, and concluded that these treatments "were probably more likely than placebo to reduce tics" [4].

\section{Transcranial Magnetic Stimulation}

Transcranial magnetic stimulation (TMS) delivers a repetitive magnetic pulse to a targeted area of the cortex. Various parameters of the magnetic stimulation (frequency, intensity, duration) have been found to modulate cortical excitability and induce sustained changes beyond the stimulation period [62]. TMS has been used in the treatment of depression but more recently has been explored as a potential treatment for tics in TS. In 1 meta-analysis of 8 studies in the literature, there was noted to be a significant reduction in tics (Hedges' $g=-$ $0.61 ; 95 \% \mathrm{CI}-0.94,-0.29)$ and OCD symptoms $(g=-0.48$; $\mathrm{CI}-0.83,-0.14)$ when all studies were assessed as a whole [63]. However, in a second analysis within the same publication, which accounted for a placebo arm, there was no significant reduction in tics seen between the 2 groups.

There are currently several ongoing placebo controlled trials evaluating the effects of TMS on tics and related conditions such as OCD (Table 2) [64]. In the Transcranial Magnetic Stimulation for Intervening in Children With Tourette's Syndrome study (TICS-CIHR), children (age 618 years) will be randomized to either repetitive TMS (rTMS) and CBIT or sham rTMS and CBIT over 3 weeks (Clinical Trials ID NCT03844919) [65]. The Multi-site Transcranial Magnetic Stimulation Therapy of the Supplementary Motor Area in Children With Tourette Syndrome trial will randomize TS patients (age 8-20) to rTMS or sham stimulation for 2 weeks (Clinical Trials ID NCT03642951) [66]. If found effective, TMS has potential as an adjunctive therapy in TS, because it seems to be generally well tolerated, with the most commonly reported side effect being headache. Further research, however, is still needed to support its safety and efficacy, especially in children with TS.

\section{Botulinum Toxin Injections}

For localized bothersome motor or phonic (vocal) tics, botulinum toxin injections can be a very useful alternative to other medical therapies. In one study, 35 patients were treated with onabotulinumtoxin A injections at a site determined by their most problematic tic [67]. Patients reported improvement in 
severity of tics based on a peak effect rating scale $(2.8 \pm 1.5$, range $0-4,0=$ no effect, $4=$ marked improvement). The mean latency of onset was 3.8 days with a mean duration of benefit of 14 weeks. Furthermore, $84 \%$ of patients reported improvement in the premonitory sensation with treatment based on a subjective percentage scale (mean reported benefit $=70.6 \%$ improvement). Complications were mild and transient and included weakness at the site of injection.

These results have been replicated in a RDBPCT of 18 patients who received botulinum toxin injections for simple motor tics [68]. Patients who received botulinum toxin injections had a $39 \%$ reduction in tics counted per minute compared to placebo which showed a $5.8 \%$ increase in tics. There was also nonsignificant improvement in the sensation of premonitory urge in this study when compared to placebo based on a patient-administered scale on premonitory urge severity (reduction of $-0.25 ; 95 \% \mathrm{CI}-0.091,0.41$, range $0-4$, in which a higher number correlates with severity).

Besides motor tics, onabotulinumtoxin A has been also used successfully in the treatment of simple and complex phonic tics. In an open-label trial, $30 \mathrm{TS}$ patients received bilateral vocal cord injections for phonic tics [69]. After treatment, 93\% of participants showed improvement in vocal tics as determined by clinical exam, with $50 \%$ of patients being tic free. The mean duration of response was about 102 days (range 20300 ). As with the other trials, there was further data to support treatment of premonitory urge (52\% of patients reported premonitory sensations before treatment, compared to $20 \%$ after treatment). Transient hypophonia was noted in $80 \%$ of patients receiving treatment.

The duration of response to botulinum injections is typically 12 to 16 weeks and requires repeated injections for optimal long-term management. The main side effect is weakness at the site of injection [4]. Botulinum injections carry several advantages over systemic medical therapy. Botulinum toxin only acts in the site of injection, and therefore, any side effects of weakness are typically localized to the injected muscles and typically resolve in a few weeks. Botulinum toxin treatment can be used safely in combination with drug therapy as it does not cause sedation or any other systemic side effects except for occasional transient flu-like symptoms [70]. Importantly, botulinum toxin appears to have some effect in treating the premonitory sensation preceding most tics, suggesting that it is not merely just masking tics by inducing local muscle weakness, but may be leading to relief via more complex peripheral mechanisms. This treatment is most suitable in cases with bothersome focal or segmental tics such as blinking or dystonic tics involving the neck (the "whiplash" tics) and shoulders or disabling phonic tics (such as loud screams or coprolalia), especially in patients who are unable to tolerate other medications or have not had a satisfactory improvement in their tics (Fig. 1) [3, 4, 71].

\section{Deep Brain Stimulation}

Deep brain stimulation (DBS) is a potential treatment reserved for patients with severe TS that has been refractory to medical treatment (Fig. 1). Although the pathophysiology of tics is not fully understood, it is thought that tics are due to dysfunction in the basal ganglia-thalamo-cortical circuits, which can be favorably modified by DBS [72]. As it is not currently FDA approved for the treatment of tics, proposed indications for DBS in the treatment of TS include the presence of high tic severity and poor symptomatic relief despite the use of at least three different classes of pharmaceutical treatments: alpha agonist, antipsychotic, and an additional class of medication such as a VMAT2 inhibitor or topiramate [73].

Multiple targets for DBS have been studied over the past 2 decades including the centromedian parafascicular complex of the thalamus, the anterior and posterior globus pallidus internus (GPi), and the anterior limb of the internal capsule (ALIC) [73, 74]. In a review of $185 \mathrm{TS}$ patients from the international DBS registry, patients were found to have $40.1 \%$ improvement on average from baseline YGTSS scores at 1 year following implantation (from $75.01 \pm 18.36$ to 41.19 \pm 20.00 ) [75]. Four targets were evaluated in this retrospective study: the anterior GPi, the posterior $\mathrm{GPi}$, the centromedian thalamic region, and the ALIC. There were no statistically significant differences seen between target groups; however, the anterior GPi showed greatest improvement with a 50.5\% reduction in the YGTSS score (from $84.33 \pm 11.32$ to $41.78 \pm$ $15.75)$, followed by a $46.3 \%$ reduction in the central thalamic region (from $74.49 \pm 2.28$ to $40.02 \pm 2.70$ ) and a $27.7 \%$ reduction in the posterior GPi (from $65.12 \pm 3.96$ to $45.65 \pm 4.68$ ); no significant change was seen with the ALIC group; howev$\mathrm{er}$, the number of participants in this group was small (4 patients) [75].

A meta-analysis of 57 studies comprising 156 TS cases showed that DBS led to a significant improvement in YGTSS scores $(52.68 \%$ reduction; interquartile range $(\mathrm{IQR})=40.83)$ [76]. Improvement in symptoms was seen across all targets, including the posterior ventral lateral GPi, anteromedial GPi, and the ALIC. Comparable improvement was seen with both the anteromedial GPi and posterior ventral lateral GPi (58.03\%; IQR = 61.09 and 55.32\%; IQR = 38.13 reduction in YGTSS score respectively). Stimulation in the ALIC region showed improvement to a lesser extent (44\%; $\mathrm{IQR}=24.58)$. A lower YGTSS score on initial evaluation was a favorable predictor of improvement (correlation coefficient $=0.337$ ). There was also suggestion that younger patients may benefit more than older patients; however, this correlation was not found to be significant [76]. Other case series and meta-analyses have demonstrated similar findings [77-79].

Few randomized control trials have evaluated the efficacy of DBS in TS. One RDBPCT assessing DBS in adults (ages 
18-60 years) did not replicate what had previously been reported in the literature [80]. In this study, 16 patients underwent DBS placement with lead placement in the anterior GPi. They were then randomized to receive stimulation or sham stimulation for 3 months. No significant difference was seen in YGTSS scores between groups at 3 months ( $1.1 \%$ reduction in the treatment group, IQR $=-23.9$ to 38.1 , compared to $0.0 \%$ change in the placebo group, IQR = - 10.6 to 4.8). Furthermore, 4 patients experienced complications because of hardware infections, and 1 had electrode misplacement. In the treatment group, 1 patient reported an episode of depression and another reported increased anxiety and worsening of tics. Notably, the treatment group patients were exposed to intensity set below side effect thresholds to maintain blinding so it was possible they were not receiving adequate stimulation. In another randomized double-blind crossover study, 15 TS patients (mean age 34.7) received GPitargeted DBS and were also randomized to receive stimulation or sham stimulation for 3 months and then switch treatment arms for an additional 3 months [81]. Compared to sham stimulation, treatment led to an average of $15.3 \%$ reduction in YGTSS scores $(95 \%$ CI 5.3, 25.3). In one of the only prospective studies evaluating DBS for the treatment of TS, 16 patients received anterior GPi DBS and were then followed by longitudinal observation for 48 months [82]. Ultimately, 12 patients completed the study, with 4 lost to follow-up. A mean $49.3 \% \pm 38.2 \%$ reduction in YGTSS was found at 48 months. The authors noted that $25 \%$ of their patients appeared to be "nonresponders"; however, those who did respond (remaining 9 patients) had a $69.5 \%$ reduction in the YGTSS suggesting that more research is needed to determine which patients are most suitable for this form of therapeutic intervention.

Typical exclusion criteria for DBS implantation include the presence of cognitive impairment, an unstable or untreated psychiatric disorder, suicidal ideation, or psychiatric inpatient hospitalization in the preceding 6 months. The decision for DBS placement and potential target should be made collectively by a multidisciplinary team composed of neurologist, neurosurgeons, psychiatrist, and neuropsychologist. Potential complications from DBS may include infection, dysarthria, paresthesia, fatigue, apathy, lethargy, and manic symptoms. Compared with other populations receiving DBS, there does appear to be a need for more frequent hardware revisions in TS patients [4, 73, 75]. The reasons for this are not clear, but some patients, particularly those with severe comorbid OCD, may repeatedly touch, scratch, or strike the impulse generator or its leads requiring revisions.

\section{Treatment of Comorbid Conditions}

Comorbid psychiatric conditions often accompany TS. The lifetime prevalence psychiatric comorbidities in TS patients is as high as $86 \% ; 72.1 \%$ of patients meet criteria for OCD or ADHD [83]. TS patients have also been found to have a higher incidence of comorbid psychopathology such as depression or anxiety, heightened stress, and poor global functioning [84].

A subanalysis of a trial pertaining to OCD has shown that patients afflicted with OCD and tics do not respond as robustly to the selective serotonin reuptake inhibitor sertraline when compared to patients with OCD without tics (posttreatment Children's Yale-Brown Obsessive Compulsive Scale score $15.5 \pm 5.3$ in the OCD-only group compared to $17.0 \pm 5.6$ in the OCD-plus-tics group) [85]. Both groups, however, did respond equally well to cognitive behavioral therapy. Patients with comorbid ADHD experience greater psychosocial stress and poorer global functioning compared to TS patients without OCD and are also more likely to carry a diagnosis of oppositional defiant disorder [84]. Although there has been concern that stimulant medications may worsen tics, studies suggest this is not always the case [18]. Although it has been shown that methylphenidate does not adversely affect tics, many parents report that initiation of central nervous system (CNS) stimulants triggers or exacerbates tics in their children. We, therefore, often prescribe anti-tic medications as first-line treatments, and when the tics are relatively well controlled, we add CNS stimulants in patients who require treatment of both tics and ADHD (Fig. 1).

\section{Conclusion}

TS is a heterogeneous and variable disorder with no 2 patients experiencing the same symptoms. Tics, the most characteristic feature of TS, can be mild or moderately troublesome, and in some cases may be associated with self-injurious behavior or become otherwise disabling. The cornerstone of any treatment is patient education and a therapeutic approach that is individualized and tailored to address those symptoms that are most troublesome or disabling to the patient. Comorbid behavioral and psychiatric conditions may worsen overall disability and adversely impact quality of life. Therefore, a holistic approach to treatment is required, targeting not only motor but also behavioral and psychiatric symptoms associated with TS. DBS should be reserved for the most refractory cases as it carries with it its own risks. Currently, there are several new and emerging treatments that are promising but require additional research (Table 2).

Acknowledgments Andrew Billnitzer, MD, declares no conflict of interest.

Joseph Jankovic, MD, has received the following research/training funding: AbbVie Inc.; Acadia Pharmaceuticals; Allergan, Inc.; Biotek; Cerevel Therapeutics; CHDI Foundation; Dystonia Coalition; Emalex Biosciences, Inc.; F. Hoffmann-La Roche Ltd.; Huntington Study Group; Medtronic Neuromodulation; Merz Pharmaceuticals; Michael J 
Fox Foundation for Parkinson Research; National Institutes of Health; Neuraly, Inc.; Neurocrine Biosciences; Parkinson's Foundation; Parkinson Study Group; Prilenia Therapeutics; Revance Therapeutics, Inc.; and Teva Pharmaceutical Industries Ltd. He has served as a consultant for Aeon BioPharma; Nuvelution Pharma, Inc.; and Teva Pharmaceutical Industries Ltd. and is on the following editorial boards: Expert Review of Neurotherapeutics; Journal of Parkinson's Disease; Medlink; Neurology in Clinical Practice; The Botulinum Journal; PeerJ; Therapeutic Advances in Neurological Disorders; Toxins; Tremor and Other Hyperkinetic Movements; Toxins; and UpToDate.

Required Author Forms Disclosure forms provided by the authors are available with the online version of this article.

\section{References}

1. Association D-5 AP. Diagnostic and statistical manual of mental disorders 2013.

2. Singer HS. Tics and Tourette syndrome. Continuum (Minneap Minn) 2019;25:936-58. https://doi.org/10.1212/CON. 0000000000000752 .

3. Jankovic J. Treatment of tics associated with Tourette syndrome. J Neural Transm 2020. https://doi.org/10.1007/s00702-019-02105w.

4. Pringsheim T, Okun MS, Müller-Vahl K, Martino D, Jankovic J, Cavanna AE, et al. Practice guideline recommendations summary: treatment of tics in people with Tourette syndrome and chronic tic disorders. Neurology 2019;92:896-906. https://doi.org/10.1212/ WNL.0000000000007466.

5. Stafford M, Cavanna AE Prevalence and clinical correlates of selfinjurious behavior in Tourette syndrome. Neurosci Biobehav Rev 2020

6. Martino D, Pringsheim TM. Tourette syndrome and other chronic tic disorders: an update on clinical management. Expert Review of Neurotherapeutics 2017. https://doi.org/10.1080/14737175.2018. 1413938 .

7. Nussey C, Pistrang N, Murphy T, Nussey C, Older B. How does psychoeducation help? A review of the effects of providing information about Tourette syndrome and attention-deficit/hyperactivity disorder 2013. https://doi.org/10.1111/cch.12039.

8. Chadehumbe MA, Brown LW. Advances in the treatment of Tourette's disorder. Curr Psychiatry Rep 2019;21:31. https://doi. org/10.1007/s11920-019-1018-z.

9. Jackson SR, Loayza J, Crighton M, Sigurdsson HP, Dyke K, Jackson GM. The role of the insula in the generation of motor tics and the experience of the premonitory urge-to-tic in Tourette syndrome. Cortex 2020. https://doi.org/10.1016/j.cortex.2019.12.021.

10. Patel N, Jankovic J, Hallett M. Sensory aspects of movement disorders. Lancet Neurol 2014. https://doi.org/10.1016/S14744422(13)70213-8.

11. Piacentini J, Woods DW, Scahill L, Wilhelm S, Peterson AL, Chang S, et al. Behavior therapy for children with Tourette disorder: a randomized controlled trial. JAMA 2010;303:1929-37. https://doi.org/10.1001/jama.2010.607.

12. Wilhelm S, Peterson AL, Piacentini J, Woods DW, Deckersbach T, Sukhodolsky DG, et al. Randomized trial of behavior therapy for adults with Tourette syndrome. Arch Gen Psychiatry 2012;69:795803. https://doi.org/10.1001/archgenpsychiatry.2011.1528.

13. McGuire JF, Piacentini J, Brennan EA, Lewin AB, Murphy TK, Small BJ, et al. A meta-analysis of behavior therapy for Tourette
Syndrome. J Psychiatr Res 2014;50:106-12. https://doi.org/10. 1016/j.jpsychires.2013.12.009.

14. Internet-based CBIT for children with chronic tics. ClinicalTrials. gov n.d. https://clinicaltrials.gov/ct2/show/NCT04087616?term= cbit\&cond=Tourette + Syndrome $\&$ draw $=2 \&$ rank $=3$ (accessed March 10, 2020).

15. Pandey S, Dash D. Progress in pharmacological and surgical management of Tourette syndrome and other chronic tic disorders. Neurologist 2019;24:93-108. https://doi.org/10.1097/NRL. 0000000000000218.

16. Pringsheim T, Marras C. Pimozide for tics in Tourette's syndrome. Cochrane Database Syst Rev 2009. https://doi.org/10.1002/ 14651858.CD006996.pub2.

17. Curtis A, Clarke CE, Rickards HE. Cannabinoids for Tourette's syndrome. Cochrane Database Syst Rev 2009. https://doi.org/10. 1002/14651858.cd006565.pub2.

18. Scahill L, Chappell PB, Kim YS, Schultz RT, Katsovich L, Shepherd E, et al. A placebo-controlled study of guanfacine in the treatment of children with tic disorders and attention deficit hyperactivity disorder. Am J Psychiatry 2001;158:1067-74. https://doi. org/10.1176/appi.ajp.158.7.1067.

19. Chappell PB, Riddle MA, Scahill L, Lynch KA, Schults R, Arnsten A, et al. Guanfacine treatment of comorbid attention-deficit hyperactivity disorder and Tourette's syndrome: preliminary clinical experience. J Am Acad Child Adolesc Psychiatry 1995;34:1140-6. https://doi.org/10.1097/00004583-199509000-00010.

20. Cummings DD, Singer HS, Krieger M, Miller TL, Mahone EM. Neuropsychiatric effects of guanfacine in children with mild Tourette syndrome: a pilot study. Clin Neuropharmacol 2002;25: 325-32. https://doi.org/10.1097/00002826-200211000-00009.

21. Tourette's Syndrome Study Group. Treatment of ADHD in children with tics: a randomized controlled trial. Neurology 2002;58: 527-36. https://doi.org/10.1212/WNL.58.4.527.

22. Murphy TK, Fernandez T V, Coffey BJ, Rahman O, Gavaletz A, Hanks CE, et al. Extended-release guanfacine does not show a large effect on tic severity in children with chronic tic disorders. J Child Adolesc Psychopharmacol 2017;27:762-70. https://doi.org/10. 1089/cap.2017.0024.

23. Du YS, Li HF, Vance A, Zhong YQ, Jiao FY, Wang HM, et al. Randomized double-blind multicentre placebo-controlled clinical trial of the clonidine adhesive patch for the treatment of tic disorders. Aust N Z J Psychiatry 2008;42:807-13. https://doi.org/10. 1080/00048670802277222

24. Weisman H, Qureshi IA, Leckman JF, Scahill L, Bloch MH. Systematic review: pharmacological treatment of tic disordersefficacy of antipsychotic and alpha-2 adrenergic agonist agents. Neurosci Biobehav Rev 2013;37:1162-71. https://doi.org/10. 1016/j.neubiorev.2012.09.008.

25. Osland ST, Steeves TDL, Pringsheim T. Pharmacological treatment for attention deficit hyperactivity disorder (ADHD) in children with comorbid tic disorders. Cochrane Database Syst Rev 2018;2018. https://doi.org/10.1002/14651858.CD007990.pub3.

26. Kuo S-H, Jimenez-Shahed J. Topiramate in treatment of tourette syndrome. Clin Neuropharmacol 2010;33:32-4. https://doi.org/10. 1097/WNF.0b013e3181c295c1.

27. Jankovic J, Jimenez-Shahed J, Brown LW. A randomised, doubleblind, placebo-controlled study of topiramate in the treatment of Tourette syndrome. J Neurol Neurosurg Psychiatry 2010;81:70-3. https://doi.org/10.1136/jnnp.2009.185348.

28. Yang CS, Zhang LL, Zeng LN, Huang L, Liu YT. Topiramate for Tourette's syndrome in children: a meta-analysis. Pediatr Neurol 2013;49:344-50. https://doi.org/10.1016/j.pediatrneurol.2013.05. 002 .

29. Sallee FR, Kurlan R, Goetz CG, Singer H, Scahill L, Law G, et al. Ziprasidone treatment of children and adolescents with Tourette's syndrome: a pilot study. J Am Acad Child Adolesc Psychiatry 
2000;39:292-9. https://doi.org/10.1097/00004583-20000300000010 .

30. Yoo HK, Joung YS, Lee JS, Song DH, Lee YS, Kim JW, et al. A multicenter, randomized, double-blind, placebo-controlled study of aripiprazole in children and adolescents with Tourette's disorder. J Clin Psychiatry 2013;74. https://doi.org/10.4088/JCP.12m08189.

31. Sallee F, Kohegyi E, Zhao J, McQuade R, Cox K, Sanchez R, et al. Randomized, double-blind, placebo-controlled trial demonstrates the efficacy and safety of oral aripiprazole for the treatment of Tourette's disorder in children and adolescents. J Child Adolesc Psychopharmacol 2017;27:771-81. https://doi.org/10.1089/cap. 2016.0026

32. Dion Y, Annable L, Sandor P, Chouinard G. Risperidone in the treatment of Tourette syndrome: a double-blind, placebocontrolled trial. J Clin Psychopharmacol 2002;22:31-9. https:// doi.org/10.1097/00004714-200202000-00006.

33. Scahill L, Leckman JF, Schultz RT, Katsovich L, Peterson BS. A placebo-controlled trial of risperidone in Tourette syndrome. Neurology 2003;60:1130-5. https://doi.org/10.1212/01.wnl. 0000055434.39968.67.

34. Peña MS, Yaltho TC, Jankovic J. Tardive dyskinesia and other movement disorders secondary to aripiprazole. Mov Disord 2011. https://doi.org/10.1002/mds.23402.

35. McCracken JT, Suddath R, Chang S, Thakur S, Piacentini J. Effectiveness and tolerability of open label olanzapine in children and adolescents with Tourette syndrome. J Child Adolesc Psychopharmacol 2008;18:501-8. https://doi.org/10.1089/cap. 2007.135.

36. Wijemanne S, Wu LJC, Jankovic J. Long-term efficacy and safety of fluphenazine in patients with Tourette syndrome. Mov Disord 2014. https://doi.org/10.1002/mds.25692.

37. Brander $\mathrm{G}$, Isomura $\mathrm{K}$, Chang Z, Kuja-Halkola R, Almqvist C, Larsson $\mathrm{H}$, et al. Association of Tourette syndrome and chronic tic disorder with metabolic and cardiovascular disorders. JAMA Neurol 2019. https://doi.org/10.1001/jamaneurol.2018.4279.

38. Savitt D, Jankovic J. Tardive syndromes. J Neurol Sci 2018. https:// doi.org/10.1016/j.jns.2018.02.005.

39. Frei K, Truong DD, Fahn S, Jankovic J, Hauser RA. The nosology of tardive syndromes. J Neurol Sci 2018. https://doi.org/10.1016/j. jns.2018.02.008

40. Jankovic J. Dopamine depleters in the treatment of hyperkinetic movement disorders. Expert Opin Pharmacother 2016;17:246170. https://doi.org/10.1080/14656566.2016.1258063.

41. Niemann N, Jankovic J. Real-world experience with VMAT2 inhibitors. Clin Neuropharmacol 2019;42:37-41. https://doi.org/10. 1097/WNF.0000000000000326.

42. Jankovic J, Jimenez-Shahed J, Budman C, Coffey B, Murphy T, Shprecher D, et al. Deutetrabenazine in tics associated with Tourette syndrome. Tremor Other Hyperkinet Mov (N Y) 2016;6: 422. https://doi.org/10.7916/D8M32W3H.

43. Porta M, Sassi M, Cavallazzi M, Fornari M, Brambilla A, Servello D. Tourette's syndrome and role of tetrabenazine: review and personal experience. Clin Drug Investig 2008;28:443-59. https://doi. org/10.2165/00044011-200828070-00006.

44. Coffey B, Jankovic J, Claassem D, Jimenez-Shahed J, Gertz B, Garofalo E, et al. Efficacy and safety of deutetrabenazine treatment for Tourette syndrome in children and adolescents: results from the ARTISTS 1 and ARTISTS 2 studies. Presented at the Tourette Association of America's Inaugural Virtual Conference. https:// tourette.org/about-tourette/virtual-conference/. Accessed 15 May 2020

45. Ondo WG, Jong D, Davis A. Comparison of weight gain in treatments for tourette syndrome: tetrabenazine versus neuroleptic drugs. J Child Neurol 2008;23:435-7. https://doi.org/10.1177/ 0883073807307108
46. Chipkin RE, Iorio LC, Coffin VL, McQuade RD, Berger JG, Barnett A. Pharmacological profile of SCH39166: a dopamine D1 selective benzonaphthazepine with potential antipsychotic activity. J Pharmacol Exp Ther 1988;247:1093-102.

47. Karlsson P, Farde L, Härnryd C, Sedvall G, Smith L, Wiesel FA. Lack of apparent antipsychotic effect of the D1-dopamine recepotr antagonist SCH39166 in acutely ill schizophrenic patients. Psychopharmacology (Berl) 1995;121:309-16. https://doi.org/10. 1007/BF02246068.

48. Gilbert DL, Budman CL, Singer HS, Kurlan R, Chipkin RE. A D1 receptor antagonist, ecopipam, for treatment of tics in Tourette syndrome. Clin Neuropharmacol 2014;37:26-30. https://doi.org/10. 1097/WNF.0000000000000017.

49. Gilbert DL, Murphy TK, Jankovic J, Budman CL, Black KJ, Kurlan RM, et al. Ecopipam, a D1 receptor antagonist, for treatment of Tourette syndrome in children: a randomized, placebo-controlled crossover study. Mov Disord 2018;33(8):1272-1280. https://doi. org/10.1002/mds.27457.

50. Ecopipam tablets to study Tourette's syndrome in children and adolescents (D1AMOND). ClinicalTrialsGov 2019.

51. Müller-Vahl KR, Schneider U, Koblenz A, Jöbges M, Kolbe H, Daldrup T, et al. Treatment of Tourette's syndrome with $\Delta 9$-tetrahydrocannabinol (THC): a randomized crossover trial. Pharmacopsychiatry 2002;35:57-61. https://doi.org/10.1055/s2002-25028.

52. Müller-Vahl KR, Schneider U, Prevedel H, Theloe K, Kolbe H, Daldrup T, et al. $\Delta$ 9-Tetrahydrocannabinol (THC) is effective in the treatment of tics in Tourette syndrome: a 6-week randomized trial. J Clin Psychiatry 2003;64:459-65. https://doi.org/10.4088/ JCP.v64n0417.

53. Thaler A, Arad S, Schleider LB-L, Knaani J, Taichman T, Giladi N, et al. Single center experience with medical cannabis in Gilles de la Tourette syndrome. Parkinsonism Relat Disord 2019;61:211-3. https://doi.org/10.1016/j.parkreldis.2018.10.004

54. A study to examine the efficacy of a therapeutic THX-110 for Tourette syndrome. ClinicalTrials.gov n.d. https://clinicaltrials. gov/ct $2 /$ show $/$ NCT03651726? recrs=abdf $\&$ type $=$ Intr\&cond $=$ Tourette+Syndrome\&draw=2\&rank=7 (accessed March 9, 2020).

55. CANNAbinoids in the Treatment of TICS (CANNA-TICS). ClinicalTrials.gov n.d. https://clinicaltrials.gov/ct2/show/ NCT03087201 recrs $=$ abdf\&type $=$ Intr\&cond $=$ Tourette + Syndrome \&draw $=2 \&$ rank=27 (accessed March 9, 2020).

56. Safety and efficacy of cannabis in Tourette syndrome. ClinicalTrials.gov n.d. https://clinicaltrials.gov/ct2/show/ NCT 03247244 ?recrs $=$ abdf\&type $=$ Intr\& cond $=$ Tourette + Syndrome \&draw $=2 \&$ rank $=4$ (accessed March 9, 2020).

57. Jiang M, van der Stelt M. Activity-based protein profiling delivers selective drug candidate ABX-1431, a monoacylglycerol lipase inhibitor, to control lipid metabolism in neurological disorders. J Med Chem 2018;61:9059-61. https://doi.org/10.1021/acs.jmedchem. $8 \mathrm{~b} 01405$.

58. Study of ABX-1431 in adult patients with Tourette syndrome or chronic motor tic disorder. ClinicalTrialsGov 2019. https:// clinicaltrials.gov/ct2/show/NCT03625453 (accessed September 15, 2019).

59. Patel H, Nguyen KH, Lehman E, Mainali G, Duda L, Byler D, et al. Use of complementary and alternative medicine in children with Tourette syndrome. J Child Neurol 2020;35:512-6. https://doi. org/10.1177/0883073820913670.

60. Hee Kim Y, Son C-G, Ku B-C, Won Lee H, Sook Lim H, Soo Lee M Herbal medicines for treating tic disorders: a systematic review of randomised controlled trials. 2014. https://doi.org/10.1186/17498546-9-6.

61. Zheng Y, Zhang ZJ, Han XM, Ding Y, Chen YY, Wang XF, et al. A proprietary herbal medicine (5-Ling granule) for Tourette 
syndrome: a randomized controlled trial. J Child Psychol Psychiatry Allied Discip 2016. https://doi.org/10.1111/jcpp.12432.

62. Guo Q, Li C, Wang J. Updated review on the clinical use of repetitive transcranial magnetic stimulation in psychiatric disorders. Neurosci Bull 2017;33:747-56. https://doi.org/10.1007/s12264017-0185-3.

63. Hsu C-W, Wang L-J, Lin P-Y. Efficacy of repetitive transcranial magnetic stimulation for Tourette syndrome: a systematic review and meta-analysis. Brain Stimul n.d.;11:1110-8. https://doi.org/10. 1016/j.brs.2018.06.002.

64. Cocchi L, Zalesky A, Nott Z, Whybird G, Fitzgerald PB, Breakspear M. Transcranial magnetic stimulation in obsessivecompulsive disorder: a focus on network mechanisms and state dependence. NeuroImage Clin 2018;19:661-74. https://doi.org/ 10.1016/j.nicl.2018.05.029.

65. TICS: transcranial magnetic stimulation for intervening in children with Tourette's syndrome (CIHR). ClinicalTrials.gov n.d. https:// clinicaltrials.gov/ct2/show/NCT03844919?recrs=abdf\&type $=$ Intr\&cond=Tourette + Syndrome $\&$ draw $=2 \&$ rank $=28$ (accessed March 9, 2020)

66. Multi-site transcranial magnetic stimulation therapy of the supplementary motor area in children with Tourette syndrome. ClinicalTrials.gov n.d. https://clinicaltrials.gov/ct2/show/ NCT03642951 ?recrs $=$ abdf\&type $=$ Intr\& cond=Tourette + Syndrome \&draw=2\&rank=8 (accessed March 9, 2020).

67. Kwak CH, Hanna PA, Jankovic J. Botulinum toxin in the treatment of tics. Arch Neurol 2000;57:1190-3. https://doi.org/10.1001/ archneur.57.8.1190.

68. Marras C, Andrews D, Sime E, Lang AE. Botulinum toxin for simple motor tics: a randomized, double-blind, controlled clinical trial. Neurology 2001;56:605-10. https://doi.org/10.1212/WNL. 56.5.605.

69. Porta M, Maggioni G, Ottaviani F, Schindler A. Treatment of phonic tics in patients with Tourette's syndrome using botulinum toxin type A. Neurol Sci 2004;24:420-3. https://doi.org/10.1007/s10072003-0201-4.

70. Jankovic J. An update on new and unique uses of botulinum toxin in movement disorders. Toxicon 2018. https://doi.org/10.1016/j. toxicon.2017.09.003.

71. Hallett M, Albanese A, Dressler D, Segal KR, Simpson DM, Truong D, et al. Evidence-based review and assessment of botulinum neurotoxin for the treatment of movement disorders. Toxicon 2013;67:94-114. https://doi.org/10.1016/j.toxicon.2012.12.004.

72. Caligiore D, Mannella F, Arbib MA, Baldassarre G. Dysfunctions of the basal ganglia-cerebellar-thalamo-cortical system produce motor tics in Tourette syndrome. PLoS Comput Biol 2017;13. https://doi.org/10.1371/journal.pcbi.1005395.

73. Casagrande SCB, Cury RG, Alho EJL, Fonoff ET. Deep brain stimulation in Tourette's syndrome: evidence to date. Neuropsychiatr Dis Treat 2019;15:1061-75. https://doi.org/10. 2147/NDT.S139368.

74. Martínez-Fernández R, Zrinzo L, Aviles-Olmos I, Hariz M, Martinez-Torres I, Joyce E, et al. Deep brain stimulation for Gilles de la Tourette syndrome: a case series targeting subregions of the globus pallidus internus. Mov Disord 2011;26:1922-30. https://doi.org/10.1002/mds.23734.
75. Martinez-Ramirez D, Jimenez-Shahed J, Leckman JF, Porta M, Servello D, Meng F-G, et al. Efficacy and safety of deep brain stimulation in Tourette syndrome: the international Tourette syndrome deep brain stimulation public database and registry. JAMA Neurol 2018;75:353-9. https://doi.org/10.1001/jamaneurol.2017. 4317.

76. Baldermann JC, Schüller T, Huys D, Becker I, Timmermann L, Jessen F, et al. Deep brain stimulation for Tourette syndrome: a systematic review and meta-analysis. Brain Stimul n.d.;9:296304. https://doi.org/10.1016/j.brs.2015.11.005.

77. Cannon E, Silburn P, Coyne T, O’Maley K, Crawford JD, Sachdev PS. Deep brain stimulation of anteromedial globus pallidus interna for severe Tourette's syndrome. Am J Psychiatry 2012;169:860-6. https://doi.org/10.1176/appi.ajp.2012.11101583.

78. Coulombe M-A, Elkaim LM, Alotaibi NM, Gorman DA, Weil AG, Fallah A, et al. Deep brain stimulation for Gilles de la Tourette syndrome in children and youth: a meta-analysis with individual participant data. J Neurosurg Pediatr 2018;23:236-46. https://doi. org/10.3171/2018.7.PEDS18300.

79. Johnson KA, Fletcher PT, Servello D, Bona A, Porta M, Ostrem JL, et al. Image-based analysis and long-term clinical outcomes of deep brain stimulation for Tourette syndrome: a multisite study. J Neurol Neurosurg Psychiatry 2019. https://doi.org/10.1136/jnnp-2019320379.

80. Welter M-L, Houeto J-L, Thobois S, Bataille B, Guenot M, Worbe $\mathrm{Y}$, et al. Anterior pallidal deep brain stimulation for Tourette's syndrome: a randomised, double-blind, controlled trial. Lancet Neurol 2017;16:610-9. https://doi.org/10.1016/S1474-4422(17) 30160-6.

81. Kefalopoulou Z, Zrinzo L, Jahanshahi M, Candelario J, Milabo C, Beigi $\mathrm{M}$, et al. Bilateral globus pallidus stimulation for severe Tourette's syndrome: a double-blind, randomised crossover trial. Lancet Neurol 2015;14:595-605. https://doi.org/10.1016/S14744422(15)00008-3.

82. Welter ML, Houeto JL, Worbe Y, Diallo MH, Hartmann A, Tezenas du Montcel S, et al. Long-term effects of anterior pallidal deep brain stimulation for Tourette's syndrome. Mov Disord 2019;34:586-8. https://doi.org/10.1002/mds.27645.

83. Hirschtritt ME, Lee PC, Pauls DL, Dion Y, Grados MA, Illmann C, et al. Lifetime prevalence, age of risk, and genetic relationships of comorbid psychiatric disorders in Tourette syndrome. JAMA Psychiatry 2015;72:325-33. https://doi.org/10.1001/ jamapsychiatry.2014.2650.

84. Lebowitz ER, Motlagh MG, Katsovich L, King RA, Lombroso PJ, Grantz H, et al. Tourette syndrome in youth with and without obsessive compulsive disorder and attention deficit hyperactivity disorder. Eur Child Adolesc Psychiatry 2012;21:451-7. https://doi. org/10.1007/s00787-012-0278-5.

85. March JS, Franklin ME, Leonard H, Garcia A, Moore P, Freeman J, et al. Tics moderate treatment outcome with sertraline but not cognitive-behavior therapy in pediatric obsessive-compulsive disorder. Biol Psychiatry 2007;61:344-7. https://doi.org/10.1016/j. biopsych.2006.09.035.

Publisher's Note Springer Nature remains neutral with regard to jurisdictional claims in published maps and institutional affiliations. 